\title{
Efeito do tratamento osmótico nas propriedades mecânicas de fatias de abacaxi (Ananas comosus) desidratadas em secador de leito fixo
}

\author{
Effect of osmotic treatment on the mechanical properties of dehydrated pineapple \\ slices (Ananas comosus) in a fixed bed dryer
}

\author{
Fernanda Rodrigues ${ }^{1}$; Paulo Henrique Mariano Marfil ${ }^{2}$ \\ ${ }^{1}$ Aluna do Programa de Mestrado em Ciência e Tecnologia de Alimentos, Instituto de Tecnologia de \\ Alimentos, Campinas, São Paulo, Brasil. E-mail: fernandarodrigues4@yahoo.com \\ ${ }^{2}$ Professor do Curso de Engenharia de Alimentos, Universidade Federal do Triângulo Mineiro, Uberaba, \\ Minas Gerais, Brasil. Orcid: https://orcid.org/0000-0002-6816-7726. E-mail: paulo.marfil@uftm.edu.br
}

\begin{abstract}
RESUMO: Um dos métodos mais antigos utilizados para conservar um alimento é a secagem. Esse método reduz a quantidade de água do alimento, inviabilizando a multiplicação de microrganismos e as reações bioquímicas de deterioração, porém, tal método pode danificar sensorialmente 0 alimento. Uma das técnicas utilizadas para minimizar os efeitos negativos da secagem é a utilização de métodos combinados, como por exemplo, o tratamento com pré-desidratação osmótica em solução hipertônica. O objetivo do trabalho foi avaliar as propriedades mecânicas das fatias de abacaxi desidratas em secador de leito fixo com e sem pré-tratamento osmótico e estudar a cinética de secagem através dos modelos matemáticos de Page e Lewis. Os modelos de Page e Lewis apresentaram bons ajustes $\left(R^{2}>0,99\right)$. A textura também foi estudada apresentando diferença estatística $(p>0,05)$ nos aspectos de dureza, elasticidade e coesividade. O processo de secagem resultou na diminuição da umidade e aumento da quantidade de sólidos solúveis e da acidez.
\end{abstract}

Palavras-chave: abacaxi desidratado, curva de secagem, pré-tratamento osmótico, textura.

ABSTRACT: One of the oldest methods used to preserve a food is drying. This method reduces the amount of water in the food, making it impossible to multiply microorganisms and the biochemical reactions of spoilage, but such method can sensorially damage the food. One of the techniques used to minimize the negative effects of drying is the use of combined methods, such as treatment with osmotic prehydration in hypertonic solution. The objective of this work was to evaluate the mechanical properties of dehydrated pineapple slices in a fixed bed dryer with and without osmotic pretreatment and to study the drying kinetics through the mathematical models of Page and Lewis. The Page and Lewis models were used, both of which presented good adjustments $\left(R^{2}>0.99\right)$. The texture was also studied, and for both samples, there was a statistical difference ( $p>0.05)$ in the aspects of hardness, elasticity and cohesiveness. For the aspects of gum, chewability and resilience there was no significant difference. The drying process resulted in decreased humidity and increased amount of soluble solids and acidity. In the sensory analysis, neither sample had a statistically significant difference, indicating that both samples were well accepted by the tasters.

Keywords: dehydrated pineapple, drying curve, osmotic pretreatment, texture. 


\section{INTRODUÇÃO}

A produção de frutas no Brasil no ano de 2017 foi estimada em 43,50 milhões de toneladas com uma área de 2,36 milhões de hectares (KIST et al., 2018). Dessa produção, o abacaxi ficou com 2,25 milhões de toneladas (FAO, 2017). Em 2018, a produção nacional foi de 2,65 milhões de toneladas, sendo a região Norte maior produtora, com participação de $34,1 \%$ na produção, seguida da região Nordeste $(33,6 \%)$, Sudeste $(26,9 \%)$, Centro-Oeste $(4,3 \%)$ e Sul $(1,1 \%)$. No mesmo ano, os principais estados produtores foram Pará, Paraíba, Minas Gerais, Rio de Janeiro e São Paulo (EMBRAPA, 2018).

O abacaxi pode ser utilizado na forma in natura ou como matéria prima para produção de diversos produtos, como doces, polpas, sucos, etc. Na forma in natura, o fruto tem maior risco de sofrer perdas devido a sua vulnerabilidade de ser amassado e da sua perecividade devido ao alto teor de umidade. A aplicação de tecnologias de conservação é uma alternativa para diminuir perdas e acrescentar valor ao produto (HOFSKY et al., 2009; FREITAS et al., 2019).

Uma das técnicas utilizadas é a secagem, que visa à redução da água de um determinado material. Essa quantidade de água é removida pela evaporação que ocorre devido à vaporização térmica ou sublimação (FERREIRA; PENA, 2010). Esse mecanismo envolve as transferências de massa, calor e quantidade de movimento. Segundo Hofsky et al. (2013), essa operação unitária é a mais utilizada como forma de conservação de alimentos, estendendo sua vida de prateleira e diminuindo seu volume. Para frutas, o processo de secagem deve preservar o sabor, cor e aroma do produto final além de apresentar textura o mais próximo da fruta in natura. Mesmo sendo uma técnica muito utilizada, a secagem pode modificar sensorialmente e nutricionalmente as características de um alimento dependendo da intensidade do processo e da composição do alimento. Dessa forma, outras técnicas são empregadas para minimizar efeitos negativos da secagem, como a utilização de métodos combinados (QUEIROZ et al., 2007).

A desidratação osmótica pode ser empregada como método combinado para diminuir os impactos desfavoráveis que a secagem provoca, como o escurecimento enzimático, a perda de aromas e a perda da cor natural dos alimentos (BORIN et al., 2008). Esse processo consiste em imergir o alimento em uma solução hipertônica para remover parcialmente a água. Essa remoção ocorre devido à diferença da pressão osmótica do alimento e do meio. O gradiente de concentração entre o meio e o alimento é a força motriz que remove a água do alimento. A maior parte da água é perdida nos primeiros 30 minutos do processo devido a essa diferença de gradiente (EGEA; LOBATO, 2014). O processo de encolhimento do tecido começa da superfície do alimento até o seu centro, camada por camada. Além da perda de água, o alimento ganha soluto da solução e perde sólidos solúveis naturais, como ácidos e vitaminas (PHISUT, 2012; GERMER et al., 2017). A desidratação osmótica quando utilizada isoladamente não é capaz de reduzir a atividade de água dos alimentos de modo que garanta sua estabilidade. Esse mecanismo reduz até $50 \%$ da massa inicial do alimento devido a sua redução de umidade (SHIGEMATSU et al., 2005). A avaliação do desempenho do processo é feita utilizando modelos matemáticos. Essa operação reduz tempo e custo de operação, permitindo um tempo adequado de secagem para cada produto (CAMELO et al., 2019).

Alguns trabalhos encontrados na literatura estudaram os efeitos da secagem com e sem tratamento osmótico em abacaxi. Gonçalves e Blume (2008) utilizaram diferentes concentrações de solução de sacarose (15, 30 e 45² Brix) para secar fatias de abacaxi. Os 
autores verificaram que as amostras que sofreram desidratação osmótica de $45^{\circ}$ Brix atingiram a atividade de água desejada mais rapidamente, além de obterem menor escurecimento enzimático e maior aceitação e preferência na análise sensorial. Tirado et al. (2017) avaliaram a secagem de abacaxi submetido a diferentes misturas de soluções osmóticas (sacarose-frutose, glucose-mel, frutose-glicose e sacarose-mel) com 40 e $50^{\circ}$ Brix. A pesquisa mostrou que as amostras que foram submetidas ao tratamento de glucose e mel tiveram resultados mais significativos na perda de água e na perda de peso, além de se mostrarem mais eficaz em ambas as concentrações. Rahim, Deb e Reshmi (2018) estudaram a secagem de abacaxi submetido a diferentes concentrações de xarope de açúcar $\left(35,40,45,50,55\right.$ e $60^{\circ}$ Brix). Os resultados mostraram que tanto o controle quanto as amostras que tiveram tratamentos de $35^{\circ}$ Brix obtiveram maior perda de peso e maior taxa de desidratação. Salazar et al. (2019) avaliaram fatias de abacaxi tratadas com sacarose a $40^{\circ}$ Brix e secas por convecção a 60 e $70^{\circ} \mathrm{C}$. Os autores constataram que as amostras secas a $70^{\circ} \mathrm{C}$ apresentaram cinética de secagem mais rápida, além de terem melhor aceitabilidade.

O método de análise do perfil de textura (TPA) é responsável por aplicar forças que deformam o alimento como simulação da compressão e corte que os dentes provocam devido à mastigação. Esse método é utilizado para medidas sensoriais e instrumentais (ANDRADE et al., 2003).

Sendo assim, o presente trabalho tem por finalidade avaliar o processo de secagem de fatias de abacaxi do tipo Pérola com e sem o uso de pré-tratamento osmótico através das curvas de secagem e avaliação mecânica dos produtos obtidos.

\section{MATERIAL E MÉTODOS}

Os abacaxis da variedade Pérola foram adquiridos em comércio local da cidade de Uberaba/MG, observando-se a coloração característica do produto maduro. Para o tratamento osmótico foi utilizado açúcar refinado também obtido em comércio local.

\section{Preparo das amostras}

Os abacaxis foram imersos em água clorada (10 ppm) por 10 minutos e lavados em água corrente com uso de sabão neutro. Em seguida, foram descascados e as coroas foram retiradas. Após essa etapa, com o auxílio de uma faca elétrica (Kfek100, Black Decker), foram fatiados na espessura de $0,5 \pm 0,2 \mathrm{~cm}$. O miolo foi retirado com o auxílio de um molde circular de aço inoxidável e as fatias foram submetidas ao processo de branqueamento através do contato em vapor de água por um minuto.

As fatias foram separadas em dois grupos: (STO) sem pré-tratamento osmótico e (CTO) com pré-tratamento osmótico

\section{Determinação do conteúdo de umidade}

A determinação da umidade do fruto in natura, após desidratação osmótica e ao final do processo de secagem, foi realizada em determinador de umidade por aquecimento infravermelho (IV2500, Gehaka) a temperatura de $100^{\circ} \mathrm{C}$ por 180 minutos, condições em que se observou o peso constante das amostras. 


\section{Acidez titulável e pH}

Para cada lote adquirido da matéria prima, foram determinados o conteúdo de acidez titulável e $\mathrm{pH}$. A leitura de $\mathrm{pH}$ foi realizada através de um pHmetro digital (PG2000, Gehaka) de acordo com AOAC (1992). A acidez titulável foi determinada por titulação com $\mathrm{NaOH}$ 0,1 M e indicador fenolftaleína 1\% (AOAC, 1990). A equação 1 foi utilizada para se obter os valores de ácido cítrico.

$$
\mathrm{C}=\frac{\mathrm{V} \times \mathrm{f} \times \mathrm{M} \times 100}{\mathrm{~A}}
$$

\section{Em que:}

- C é o teor de ácido cítrico (\%);

- V é o volume gasto de hidróxido de sódio 0,1 M;

- f é o fator de correção do $\mathrm{NaOH}$;

- M é a molaridade da solução de hidróxido de sódio 0,1 M;

- A é o volume da amostra $(\mathrm{mL})$ ou massa $(\mathrm{g})$.

\section{Preparo da solução osmótica}

A solução osmótica foi preparada aquecendo um litro de água e acrescentando 400 $\mathrm{g}$ de sacarose. Essa etapa foi feita sob agitação manual até atingir o valor de $40{ }^{\circ}$ Brix determinado por um refratômetro portátil digital (Q767D, Quimis $\left.{ }^{\circledR}\right)$ (AOAC, 1992).

As fatias de abacaxi do grupo CTO foram imersas na solução e permaneceram por um período de duas horas. As fatias de abacaxi de ambos os grupos (STO e CTO) foram desidratadas em secador convectivo de leito fixo. O teor de sólidos solúveis foi determinado nas amostras in natura e após a secagem para amostras CTO e STO.

\section{Secador convectivo de leito fixo}

A secagem ocorreu na temperatura de $40,0 \pm 6,4^{\circ} \mathrm{C}$. A velocidade do ar foi de 0,45 $\mathrm{m} / \mathrm{s}$ e medida com um anemômetro (TAFR - 190, INSTRUTHERM). As bandejas do secador foram rotacionadas de meia em meia hora para garantir que todas as amostras secassem de maneira homogênea. As amostras foram secas até obtenção do peso constante. Os ensaios ocorreram em duplicata (Bandeja 1 e Bandeja 2).

\section{Modelos matemáticos}

As curvas de razão de umidade (Adm) em função do tempo (t) foram obtidas e os modelos de Lewis e Page foram ajustados (equações 2 e 3, respectivamente) em que $\mathrm{k} e$ n são parâmetros de ajuste dos modelos, sendo $\mathrm{K}$ a constante de secagem específica e no coeficiente do modelo (COELHO et al., 2019).

$$
\begin{aligned}
& A d m=\exp ^{(-k t)} \\
& A d m=\exp ^{-k t^{\wedge} n}
\end{aligned}
$$




\section{Análise de perfil de textura (TPA)}

As propriedades mecânicas das amostras foram determinadas através da análise de perfil de textura (TPA) em um texturômetro de modelo TA.XT.plus (Stable Microsystems Ltd., Godalming, UK) acoplado a um probe esférico de $40 \mathrm{~mm}$. As amostras foram colocadas em uma base plana e o corpo de prova cilíndrico foi utilizado para comprimi-las duas vezes. A velocidade de pré teste foi de $1 \mathrm{~mm} / \mathrm{s}$, a velocidade de teste de $2 \mathrm{~mm} / \mathrm{s}$ e a velocidade pós teste de $5 \mathrm{~mm} / \mathrm{s}$ com compressão das amostras de 40\%. Tais parâmetros foram utilizados com base em trabalhos encontrados na literatura. A velocidade de teste foi definida devido a trabalhos que estudaram secagem de fatias de maçã (MARTYNENKO; JANASZEK, 2014), desidratação osmótica de frutas cristalizadas (VILELA et al., 2016) e secagem de abacaxi (SALAZAR et al., 2019). Compressões acima de $70-80 \%$ quebram a amostra por completo, imitando o processo de mastigação. Já os níveis de deformação entre $20-50 \%$ não quebram as amostras e são utilizados para obter valores de dureza, elasticidade, gomosidade ou mastigabilidade, coesão e seus derivados. Os parâmetros de dureza, elasticidade, coesividade, gomosidade, mastigabilidade e resiliência foram obtidos.

\section{RESULTADOS E DISCUSSÃO}

A Tabela 1 apresenta os valores obtidos com as análises químicas realizadas.

Tabela 1 - Análises químicas das fatias de abacaxi in natura e após a secagem (com e sem tratamento osmótico).

\begin{tabular}{lccc}
\hline & Abacaxi in natura & $\begin{array}{c}\text { STO (após a } \\
\text { secagem) }\end{array}$ & $\begin{array}{c}\text { CTO (após a } \\
\text { secagem) }\end{array}$ \\
\hline $\begin{array}{l}\text { Umidade (\% b.u) } \\
\begin{array}{l}\text { Acidez (\% ácido } \\
\text { cítrico) }\end{array}\end{array}$ & $84,55^{\mathrm{a}} \pm 3,21$ & $20,83^{\mathrm{b}} \pm 1,47$ & $18,07^{\mathrm{c}} \pm 1,32$ \\
$\begin{array}{l}\text { Sólidos solúveis } \\
\text { totais }\end{array}$ & $1,13^{\mathrm{a}} \pm 0,22$ & $1,82^{\mathrm{b}} \pm 0,51$ & $1,52^{\mathrm{b}} \pm 0,20$ \\
$\mathrm{pH}$ & $13,40^{\mathrm{a}} \pm 1,10$ & $71,35^{\mathrm{b}} \pm 1,39$ & $81,13^{\mathrm{c}} \pm 1,11$ \\
& $4,01^{\mathrm{a}} \pm 0,05$ & $3,95^{\mathrm{a}} \pm 0,32$ & $4,20^{\mathrm{a}} \pm 0,11$ \\
\hline
\end{tabular}

abcMédias com diferentes letras são diferentes estatisticamente entre si pelo teste de Tukey. $\mathrm{P}<0,05$.

O teor de umidade do abacaxi in natura está próximo dos valores encontrados por Ramos et al. (2008) que foi de 86,50 \%. A umidade está relacionada com o grau em que o fruto se encontra maduro. Após o processo de secagem, o teor de umidade diminuiu. Tal fato é explicado pelo próprio processo de secagem, o qual remove água do produto, diminuindo sua umidade. De acordo com Ranken (1993), abacaxis desidratados apresentam umidade entre $15 \%$ e $30 \%$. Autores como Ramos et al. (2008) obtiveram uma umidade após a desidratação de abacaxi de $20,60 \%$, que está dentro do encontrado para as amostras em estudo.

Os resultados mostram que o abacaxi que teve pré-tratamento osmótico apresentou um teor de umidade menor do que o abacaxi que não sofreu pré-tratamento osmótico. Esse resultado comprova que amostras que sofrem tratamento osmótico perdem mais água do que as que não sofrem, auxiliando no processo de secagem e diminuindo o gasto de energia. 
Os principais ácidos que contribuem na análise de acidez total são o cítrico $(80 \%)$ e o málico (20\%) (MACHADO et al., 2012). A acidez titulável total é expressa em porcentagem de ácido cítrico. De acordo com Costa (2002) e Carvalho e Botrel (1996), a acidez total titulável do abacaxi in natura adequada está na faixa de $0,6 \%$ a 1,6\% de ácido cítrico. Os autores ainda afirmam que, para o $\mathrm{pH}$, a faixa ideal está entre 3,7 e 3,9. Assim, para o abacaxi in natura, os resultados da análise estão próximos dos valores encontrados na literatura.

A variação na acidez total pode ser explicada na maturação da fruta antes da secagem. As frutas perdem acidez durante o processo de amadurecimento. A secagem reduz o teor de umidade e a concentração de alguns compostos e nutrientes, como os ácidos orgânicos. Esse fato pode ser observado no presente trabalho, no qual o valor de acidez total no abacaxi in natura é menor do que no abacaxi desidratado. Esse fato pode ser comprovado nos estudos de Machado et al. (2012) e Ramos et al. (2008).

Os valores de sólidos solúveis totais também estão próximos aos valores encontrados por Giacomelli (1982), que foi de 14 a $16^{\circ}$ Brix e por Ramos et al. (2008) que foi de $13,8^{\circ}$ Brix. Com o processo de secagem esse valor aumentou. Tal fato se deve a maior concentração de açúcar na fruta.

$\mathrm{O}$ pH não se alterou com relação as amostras que foram secas com uso ou não de pré-tratamento. Resultados semelhantes foram encontrados nos trabalhos de Ranken (1993) e Ramos et al. (2008).

Os modelos matemáticos de Lewis e de Page foram ajustados aos dados experimentais obtidos para o grupo STO e CTO. As curvas apresentadas nas Figuras 1 e 2 representam a variação da umidade em função do tempo para cada grupo e modelo.

Figura 1. Curvas de secagem das fatias de abacaxi sem pré-tratamento osmótico (STO).

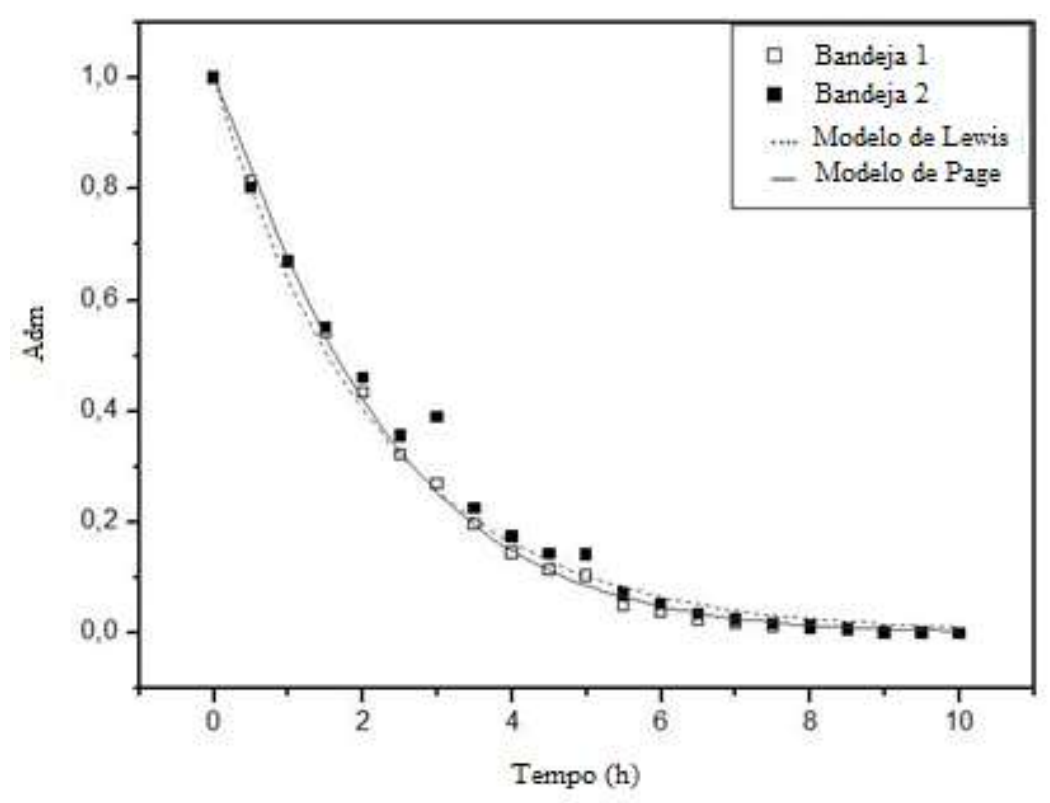


Figura 2. Curvas de secagem das fatias de abacaxi com pré-tratamento osmótico (CTO).

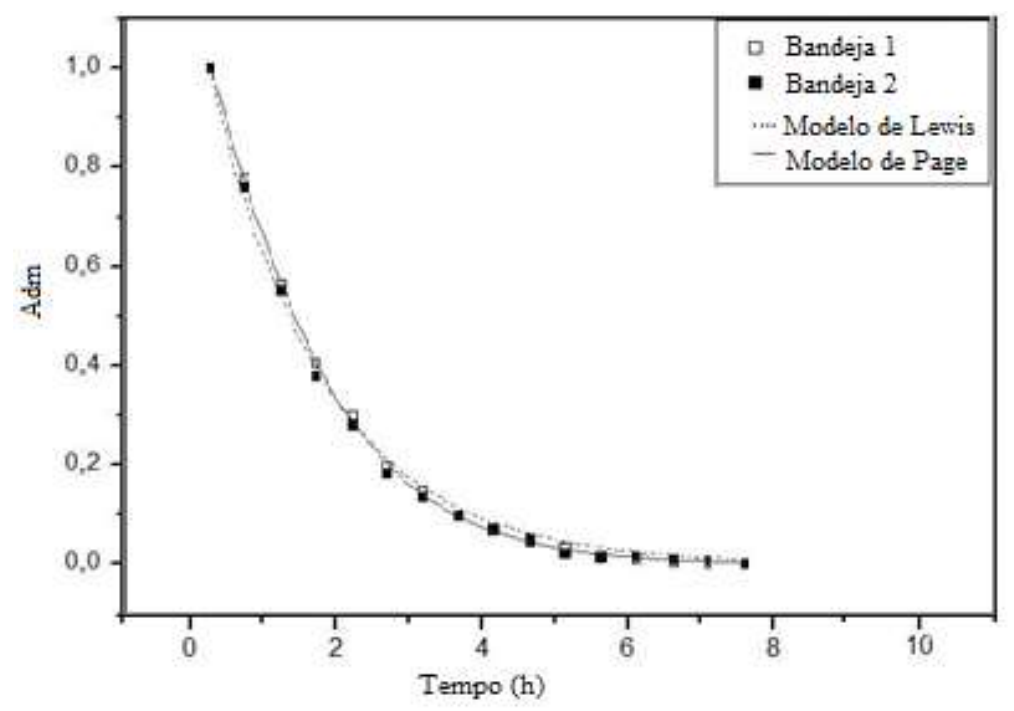

A Tabela 2 apresenta os parâmetros de ajuste para os modelos escolhidos. Notase que ambos os modelos apresentaram resultados satisfatórios, pois os valores encontrados do coeficiente de determinação $\left(R^{2}\right)$ foram maiores que 0,99; porém, 0 modelo de Page apresentou maior valor $(0,998)$. Estudos de secagem realizados por Martinazzo et al. (2007) utilizando capim-limão, Babalis et al. (2006) utilizando figo da índia e Hofsky et al. (2009) utilizando abacaxi em diferentes temperaturas de secagem também apresentaram valores elevados de $\mathrm{R}^{2}$ para o modelo de Page. Nota-se também que o parâmetro "k" obteve maior valor para o modelo de Lewis. Tal parâmetro indica a constante de taxa de secagem que se relaciona com a difusividade no processo (MADUREIRA et al., 2012). O parâmetro "k" qualifica o efeito da temperatura nas amostras e tem relação com a difusividade efetiva ao longo do processo de secagem. Valores maiores de " $k$ " indicam que o valor de água de equilíbrio foi alcançado em um tempo menor, o que pode ser observado nas amostras CTO. Resultados semelhantes foram encontrados por Melo (2008) ao estudar o efeito da secagem na polpa de mandacaru e por Hii et al. (2009) ao estudar a secagem de grãos de cacau (MADUREIRA et al., 2012).

As amostras que tiveram pré-tratamento osmótico secaram em um período de tempo menor do que aquelas que não receberam tratamento pré-osmótico (7,5 e 10 horas, respectivamente). Segundo Borges e Menegalli (1994), que estudaram a influência da desidratação osmótica na secagem de manga, durante o tratamento pré-osmótico, 0 açúcar, que está em solução, está em maiores concentrações na superfície da amostra, auxiliando na difusão da água e acelerando a secagem, ou seja, o produto que foi submetido ao tratamento pré-osmótico foi para a secagem com menor teor de umidade.

Tabela 2. Dados dos ajustes utilizando modelos de Lewis e de Page em secador convectivo com (CTO) e sem pré-tratamento osmótico (STO).

\begin{tabular}{cccccc}
\hline & \multicolumn{3}{c}{ Modelo de Lewis } & \multicolumn{3}{c}{ Modelo de Page } \\
\cline { 2 - 6 } & $\mathrm{R}^{2}$ & $\mathrm{~K}$ & $\mathrm{R}^{2}$ & $\mathrm{k}$ & $\mathrm{n}$ \\
STO & 0,9948 & $0,453 \pm 0,009$ & 0,9988 & $0,394 \pm 0,001$ & $1,138 \pm 0,020$ \\
CTO & 0,9963 & $0,622 \pm 0,013$ & 0,9998 & $0,566 \pm 0,005$ & $1,136 \pm 0,011$ \\
\hline
\end{tabular}


A Tabela 3 apresenta os dados que foram obtidos através do estudo da reologia por compressão na Análise de Perfil de Textura (TPA).

Tabela 3. Análise de Perfil de Textura (TPA) das amostras.

\begin{tabular}{ccccc}
\hline & CTO & \multicolumn{2}{c}{ STO } \\
\cline { 2 - 5 } & Média \pm desvio & CV $(\%)$ & Média \pm desvio & CV (\%) \\
\hline Dureza (N) & $3873,98^{\mathrm{a}} \pm 2030,45$ & 52,43 & $1804,55^{\mathrm{b}} \pm 844,96$ & 46,82 \\
Elasticidade (\%) & $0,74^{\mathrm{a}} \pm 0,09$ & 11,74 & $0,98^{\mathrm{b}} \pm 0,05$ & 5,60 \\
Coesividade (-) & $0,53^{\mathrm{a}} \pm 0,16$ & 29,79 & $0,84^{\mathrm{b}} \pm 0,04$ & 4,98 \\
Gomosidade & $2207,09^{\mathrm{a}} \pm 1450,50$ & 65,72 & $1490,98^{\mathrm{a}} \pm 657,79$ & 44,12 \\
Mastigabilidade (-) & $1668,79^{\mathrm{a}} \pm 1174,99$ & 70,41 & $1456,68^{\mathrm{a}} \pm 628,62$ & 43,15 \\
Resiliência (-) & $0,43^{\mathrm{a}} \pm 0,20$ & 46,02 & $0,44^{\mathrm{a}} \pm 0,11$ & 24,89 \\
\hline ab Médias com letras diferentes nas mesmas linhas mostram diferença significativa entre si pelo teste \\
ANOVA ( $\mathrm{p}<0,05)$.
\end{tabular}

A propriedade mecânica das frutas está ligada a estrutura celular. A estrutura da parede celular está relacionada com a composição de pectina em sua estrutura externa, chamada de lamela média. Tal estrutura promove a ligação de células entre si e varia com a maturação da fruta. A pectina é sensível ao calor e pode mudar a sua composição na lamela média dependendo da intensidade da desidratação osmótica ou secagem (EGEA; LOBATO, 2014).

De acordo com Bourne (1978), as características de uma análise de textura apresentam vários parâmetros de comparação, como dureza, elasticidade, coesividade, mastigabilidade, entre outros. Para o parâmetro de dureza nota-se que as amostras STO apresentaram valor menor do que as amostras CTO $(p<0,05)$. Tal resultado mostra que a força necessária durante a compressão da primeira mordida será maior para as amostras que obtiveram valores maiores de dureza, ou seja, as amostras que foram tratadas com pré-desidratação osmótica. Para os valores de elasticidade, nota-se que as amostras STO apresentaram valores maiores $(p<0,05)$. Tal fato indica que a recuperação da amostra em uma deformação é maior do que a amostra que sofreu tratamento de pré-desidratação osmótica. Para os valores de coesividade, observou-se que as amostras STO apresentaram valores maiores $(p<0,05)$, ou seja, as amostras resistem mais as forças externas garantindo que o material não se fragmente. Para os valores de resiliência, gomosidade e mastigabilidade, as amostras não se diferenciaram estatisticamente $(p>0,05)$.

A plasticidade e a incorporação de água na matriz dos tecidos dos frutos estão relacionadas com a textura. A incorporação de água depende da quantidade de sólidos solúveis e insolúveis presente na matriz (TORREGGIANI; BERTOLO, 2001). Para frutos, a parede celular é um fator que determina a textura. As amostras que receberam prédesidratação osmótica absorveram mais sólidos, e consequentemente perderam mais água do que as amostras que não receberam. Esse fato explica os resultados encontrados na análise de textura. Quanto mais água o alimento perde e quanto mais sólidos o alimento ganha, mais rígida a superfície fica.

\section{CONCLUSÕES}

O conteúdo de umidade das fatias de abacaxi diminuiu devido a evaporação de água durante o processo de secagem enquanto o teor de sólidos solúveis totais aumentou 
devido a maior concentração de açúcares. A acidez total titulável, expressa em ácido cítrico, também aumentou com a desidratação.

Os modelos matemáticos de Lewis e Page se mostraram adequados para representar o processo de secagem das fatias de abacaxi $\left(R^{2}>0,99\right)$.

Com a utilização da desidratação osmótica como pré-tratamento, o tempo de secagem foi menor do que para as amostras que não sofreram pré-desidratação osmótica. Tal fato mostra que o pré-tratamento auxilia na redução do tempo de secagem e consequentemente na economia de energia.

Houve diferença estatística nos ensaios mecânicos para os testes de dureza, elasticidade e coesividade das amostras CTO e STO.

\section{REFERÊNCIAS}

AOAC. Association of Official Analytical Chemists. Official methods of analysis. 15. ed. Arlington, 1990.

AOAC. Association of Official Analytical Chemists. Official methods of analysis of the Association of the Agricultural Chemists. 12. ed. Washington, 1992.

ANDRADE, S. A. C.; METRI, J. C.; BARROS NETO, B.; GUERRA, N. B. Desidratação osmótica do Jenipapo (Genipa americana L.). Food Science and Technology, v. 33, n. 2, p. 276-281, 2003.

BABALIS, S. J. et al. Avaliação de modelos de secagem em camada fina para descrever cinética de secagem de figos (Ficus carica). Journal of Food Engineering, v. 75, n. 2, p. 205-214, 2006.

BORIN, I.; FRASCARELI, E. C.; MAURO, M. A.; KIMURA, M. Efeito do pré-tratamento osmótico com sacarose e cloreto de sódio sobre a secagem convectiva de abóbora.

Ciência e Tecnologia de Alimentos, v. 28, n. 1, p. 39-50, 2008.

BORGES, S. V.; MENEGALLI, F. C. Influência da desidratação osmótica sobre a cinética de secagem de manga. Pesquisa Agropecuária Brasileira, v. 29, n. 4, p. 637-642, 1994.

BOURNE, M. C. Texture profile analysis. Food Technology, v. 32, n. 7, p. 62-66, 1978.

CAMELO, R. S. S.; PAES, J. L.; BRAZ, M. R. S.; BRUGGIANESI, G.; GUIMARÃES, C. L. Kinetics drying of silver banana (Musa spp.) in hybrid dryer. Revista Ciência

Agronômica, v. 50, n. 3, p. 353-360, 2019.

CARVALHO, V. D.; BOTREL, N. Características da fruta para exportação. In: BRASIL. Ministério da Agricultura e Abastecimento. Abacaxi para exportação: procedimentos de colheita e pós-colheita. Brasília: EMBRAPA, 1996. 41 p.

COELHO, B. E. S.; SÁ, C. H.; SILVA, L. F. M.; SOUSA, K. S. M.; MACHADO, N. S. Ajustes de modelos matemáticos a curva de secagem da banana cv. Terra com uso de energia solar térmica sob exposição direta. Revista Craibeiras de Agroecologia, v. 4, n. 1, p. e7688, 2019. 
COSTA, J. Influência da atmosfera modificada ativa sobre a qualidade do abacaxi "Perola" minimamente processado. Dissertação (Mestrado em Ciência dos Alimentos) - Universidade Federal de Lavras, Lavras, MG, 2002.

EGEA, M. B.; LOBATO, L. P. A desidratação osmótica como pré-tratamento para frutas e hortaliças. Revista do Instituto Adolfo Lutz, v. 73, n. 4, p. 316-324, 2014.

EMBRAPA. Empresa Brasileira de Pesquisa Agropecuária, 2018. Disponível em: https://www.embrapa.br/. Acesso em: 24 mar. 2020.

FAO. Food and Agriculture Organization, 2017. Disponível em: http://www.faostat.fao.org. Acesso em: 24 ago. 2019.

FERREIRA, M. F. P.; PENA, R. S. Estudo da secagem da casca do maracujá amarelo. Revista Brasileira de Produtos Agroindustriais, v. 12, n. 1, p. 15-28, 2010.

FREITAS, E. D. F.; LOPES, L. L.; ALVES, S. M. F.; CAMPOS, A. J. Efeito da maltodextrina no sumo da polpa de abacaxi 'Pérola' atomizado. Revista de Ciências Agrárias, v. 42, n. 1, p. 271-280, 2019.

GIACOMELLI, E. J. Expansão da abacaxicultura no Brasil. Campinas: Fundação Cargill, 1982.

GONÇALVES, A. A.; BLUME, A. R. Efeito da desidratação osmótica como tratamento preliminar na secagem do abacaxi. Estudos Tecnológicos, v. 4, n. 2, p. 124-134, 2008.

HII, C. L. et al. Cinética de secagem de camada fina de cacau e qualidade do produto seco. Biosystems engineering, v. 102, n. 2, p. 153-161, 2009.

HOFSKY, A. V.; GOMES, J. P.; BARROS NETO, A. L.; SILVA, F. L. H.; ALMEIDA, F. A. C. Cinética de Secagem de Abacaxi CV Pérola em Fatias. Revista Brasileira de Produtos Agroindustriais, v.11, n.2, p.123-128, 2009.

HOFSKY, A. V.; SILVA, F. L. H.; GOMES, J. P.; SILVA, O. S.; CARVALHO, J. P. D.; LIMA, E. E. Cinética de secagem do resíduo de abacaxi enriquecido. Revista Brasileira de Engenharia Agrícola e Ambiental, v. 17, n. 6, p. 640-646, 2013.

KIST, B. B.; CARVALHO, C.; TREICHEL, M.; SANTOS, C. E. Anuário brasileiro da fruticultura 2018. Santa Cruz do Sul: Editora Gazeta Santa Cruz, 2018. 88 p.

MACHADO, A. M.; SOUZA, M. C.; JUNQUEIRA, M. S.; SARAIVA, S. H.; TEIXEIRA, L. J. Q. Cinética de secagem do abacaxi cv. Pérola. Enciclopédia Biosfera, v. 8, n. 15, p. 428437, 2012.

MADUREIRA, I. A.; FIGUEIRÊDO, R. M. F.; QUEIROZ, A. J. M.; SILVA FILHO, E. D. Cinética de secagem da polpa do figo da índia. Revista Brasileira de Produtos

Agroindustriais, v. 14, n. especial, p. 525-534, 2012.

MARTINAZZO, A. P.; CORRÊA, P. C.; RESENDE, O.; MELO, E. C. Análise e descrição matemática da cinética de secagem de folhas de capim-limão. Revista Brasileira de Engenharia Agrícola e Ambiental, v. 11, n. 3, p. 301-306, 2007. 
MARTYNENKO, A.; JANASZEK, M. A. Texture changes during drying of Apple slices. Drying Technology, v. 32, n. 5, p. $567-577,2014$.

MELO, K. S. Secagem da polpa do mandacaru. Dissertação (Mestrado em Engenharia de Alimentos) - Universidade Federal de Campina Grande, Campina Grande, PB, 2008.

PHISUT, N. Factors affecting mass transfer during osmotic dehydration os fruits. International Food Research Journal, v.19, n.1, p.7-18, 2012.

QUEIROZ, V. A. V.; BERBERT, P. A.; MOLINA, M. A. B. M.; GRAVINA, G. A.; QUEIROZ, L. R.; DELIZA, R. Desidratação por imersão-impregnação e secagem por convecção de goiaba. Pesquisa agropecuária brasileira, v. 42, n. 10, p. 1479-1486, 2007.

RAHIM, A., DEB, P.; RESHMI, N. P. Study on quality analysis of osmotic dehydrated pineapple slice with different sugar syrup concentrations during storage. The Pharma Innovation Journal, v. 7, n. 12, p. 159-162, 2018.

RAMOS, A. M.; QUINTERO, A. C. F.; FARAONI, A. S.; SOARES, N. F. F.; PEREIRA, J. A. M. Efeito do tipo de embalagem e do tempo de armazenamento nas qualidades físico química e microbiológica de abacaxi desidratado. Alimentos e Nutrição, v. 19, n. 3, p. 259-269, 2008.

RANKEN, M.D. Manual de industrias de los alimentos. Zaragoza: Acribia, 1993.

SALAZAR, D. M.; ÁLVAREZ, F. C.; ACURIO, L. P.; PEREZ, L. V.; ARANCIBIA, M. Y.; CARVAJAL, M. G. et al. Osmotic concentration of pineapple (Caynne lisse) as a pretreatment for convection drying. IOP Conference Series: Earth and Environmental Science, v. 292, 2019.

SHIGEMATSU, E.; EIK, N. M.; KIMURA, M.; MAURO, M. A. Influência de pré-tratamentos sobre a desidratação osmótica de carambolas. Food Science and Technology, v. 25, n. 3, p. 536-545, 2005.

TIRADO, D. F. KEVIN J. GONZÁLEZ-MORELO, K. J. G.; PUERTA, M. J.; AHUMADA, O. Y.; CORREA, D. A. Osmotic Dehydration and Hot-Air Drying of Pineapple (Ananas comosus). International Journal of Engineering and Technology, v. 9, n. 6, p. 41934202, 2017.

TORREGGIANI, D.; BERTOLO, G. Osmotic treatments in fruit processing: chemical, physical and structural effects. Journal of Food Engineering, Oxford, v. 49, n. 2, p. 247256, 2001.

VILELA, A.; SOBREIRA, C.; ABRAÃO, A. S.; LEMOS, A. M.; NUNES, F. M. Texture quality of candied fruits as influenced by osmotic dehydration agents. Journal of Texture Studies, v. 47, n. 3, p. $239-252,2016$. 